\title{
Clinical significance of the diverse interlobar veins hidden in the upper oblique fissure
}

\author{
Xinfeng Xu ${ }^{1 \#}$, Jun Wang ${ }^{1 \# \wedge}$, Qiang Liu ${ }^{1}$, Wei Wen ${ }^{1}$, Hai Xu' ${ }^{2}$, Wei Zhang ${ }^{2}$, Quan Zhu ${ }^{1}$, Yijiang Chen ${ }^{1}$, \\ Liang Chen ${ }^{1}$
}

${ }^{1}$ Department of Thoracic Surgery, The First Affiliated Hospital of Nanjing Medical University, Nanjing, China; ${ }^{2}$ Department of Radiology, The First Affiliated Hospital of Nanjing Medical University, Nanjing, China

Contributions: (I) Conception and design: X Xu, J Wang; (II) Administrative support: Y Chen, L Chen; (III) Provision of study materials or patients: J Wang, W Wen, Q Zhu; (IV) Collection and assembly of data: Q Liu, H Xu, W Zhang; (V) Data analysis and interpretation: X Xu, J Wang; (VI) Manuscript writing: All authors; (VII) Final approval of manuscript: All authors.

\#These authors contributed equally to this work.

Correspondence to: Yijiang Chen, MD, PhD; Liang Chen, MD. Department of Thoracic Surgery, The First Affiliated Hospital of Nanjing Medical University, No. 300 Guangzhou Rd., Nanjing 210029, China. Email: chenyjnjmu@163.com; clbright0909@njmu.edu.cn.

\begin{abstract}
Background: The interlobar veins hidden in the upper oblique fissure (UOF) of the right lung are usually mismanaged cursorily according to the target lobe, which results in accidental injury of the interlobar veins and complications. The detailed classification of interlobar veins based on surgical anatomical analysis is of great clinical significance.
\end{abstract}

Methods: Three-dimensional computed tomography bronchography and angiography (3D-CTBA) reconstructed images of 398 patients from January 2019 to June 2020 were retrospectively analyzed. The interlobar veins in the UOF were observed and classified according to their morphology and distribution. The classification model was further validated in 153 patients who underwent surgery involving dissection of the UOF, and related surgical results were analyzed.

Results: The distribution of interlobar veins was diverse, and the general morphology could be divided into 2 main categories and 30 subtypes in the 3D-CTBA images of the 398 patients. Analysis of the 153 patients' surgical data showed that 60 patients suffered from interlobar vein injury. Interlobar veins hidden in an incomplete UOF were the most susceptible to accidental damage $\left(\chi^{2}=12.856, \mathrm{P}=0.020\right)$. A receiver operating characteristic (ROC) curve analysis showed that an interlobar vein diameter larger than $2.4 \mathrm{~mm}$ for the oblique fissure interlobar vein type or less than $2 \mathrm{~mm}$ for the mediastinal interlobar vein type was associated with a higher risk of injuries $(\mathrm{P}<0.001)$.

Conclusions: The diversity of interlobar veins and the completeness of the UOF were noteworthy risk factors in surgery involving dissection of the UOF.

Keywords: Interlobar vein; upper oblique fissure (UOF); three-dimensional computed tomography bronchography and angiography (3D-CTBA)

Submitted Sep 16, 2021. Accepted for publication Nov 30, 2021.

doi: $10.21037 / \mathrm{atm}-21-4913$

View this article at: https://dx.doi.org/10.21037/atm-21-4913

^ ORCID: Xinfeng Xu, 0000-0002-9888-5630; Jun Wang, 0000-0002-5975-542X. 


\section{Introduction}

The upper oblique fissure (UOF) potentially separates the posterior segment of the right upper lobe (RUL) and the superior segment of the right lower lobe (RLL) (1). Existing reports reveal that approximately $70 \%$ of UOFs are not fully developed (2), and 39\% of patients with an incomplete UOF have venous variation (3). Since most right pulmonary operations involve the fissure crest, where the horizontal fissure meets the oblique fissure, and where the interlobar veins are embedded, cursory disposal of this region inevitably causes accidental injury during surgery. However, the distribution of right top pulmonary veins (RTPVs) hidden in the UOF has not been studied thoroughly; to the best of our knowledge, there are no reports on the classification of interlobar veins in the UOF.

Preoperative three-dimensional computed tomography bronchography and angiography (3D-CTBA) allows visualization of anatomical structures and is becoming an indispensable tool in thoracic surgery $(4,5)$. In this study, 3D-CTBA was used to analyze the subtypes of interlobar veins hidden in the UOF. The clinical data of patients who underwent surgery in our center were collected to investigate the relationship between interlobar vein subtypes and accidental injury. We present the following article in accordance with the STROBE reporting checklist (available at https://atm.amegroups.com/article/view/10.21037/atm$21-4913 / \mathrm{rc})$.

\section{Methods}

\section{Study design and patient collection}

This retrospective cohort study was carried out following the Declaration of Helsinki (as revised in 2013). The study protocol was approved by the Ethics Committee of The First Affiliated Hospital of Nanjing Medical University (2021-SR-164), and informed consent was obtained from each patient. Patients who underwent thoracoscopic surgery from January 2019 to June 2020 in the Department of Thoracic Surgery were enrolled. The inclusion criteria were as follows: (I) age $\geq 18$ years old; (II) diagnosis of lung cancer; and (III) a right UOF requiring management during thoracoscopic surgery. Records with incomplete imaging data or lesions blurring the identification of interlobar veins were excluded. Records with incomplete videos of the operation with failure to show the upper right oblique fissure were excluded from the surgical data analysis. The flow diagram is shown in Figure 1.

\section{Types of interlobar veins}

According to the venous origin, the interlobar veins hidden in the UOF of the right lung could be classified as oblique fissure-type interlobar veins (OFIVs) and mediastinaltype interlobar veins (MIVs). The OFIVs originated from the central vein (Central. V) or $\mathrm{V}^{2} \mathrm{c}$, ran between the RUL and the RLL, and entered the UOF (Figure $2 A, 2 B$ ). The diameter of the OFIV was measured at the origin in the lung window on contrast-enhanced computed tomography (CT) (Figure 2C). The MIVs originated from the inferior pulmonary vein, $\mathrm{V}^{6}$, or the left atrium and entered the UOF posterior to the bronchus intermedius (BI) (Figure 2D,2E). The diameter of the MIV was measured in the same way as OFIV (Figure 2F). The branches of the interlobar veins were named after the corresponding pulmonary segment where the vein drained. For instance, if the intrasegmental vein $\left(S^{1} a\right)$ [Intra.V $\left(S^{1} a\right)$ ], the Intra.V $\left(S^{2} a\right)$, and $S^{2}$ terminal vein $\left(V^{2} t\right)$ drained to the interlobar vein, the subtype was named $V^{2} t+\operatorname{Intra} . V\left(S^{1} a\right)+\operatorname{Intra} . V\left(S^{6} a\right)$. Subtype modeling was based on the data of all branch types.

\section{Definition of fissure development}

Fissure development was estimated according to Craig and Walker's criteria, which combine the degree of completeness of the fissures and the location of the pulmonary artery at the base of the oblique fissure (6). A complete UOF is formed by the intact interlobar pleura separating the RUL and RLL. An incomplete UOF refers to the partial fusion of the RUL with the RLL, which requires dissection of the interlobar pleura to expose the intermedial arterial trunk (IAT) or interlobar vein. Fissure agenesis refers to the total absence of the interlobar pleura, which leads to extreme difficulty in exposing the IAT or interlobar vein at the location of the crest.

\section{Analysis of interlobar vein injuries}

The above interlobar vein subtypes were further analyzed regarding accidental injury correlated with surgery. In patients with a clear display of interlobar vein branches in a complete UOF, when the branches distributed at the nontarget surgical region were mistransected, accidental injury was recorded. In patients with incomplete or absent interlobar fissures, the distribution of interlobar veins on 3D-CTBA images and the scope of surgical resection were combined to comprehensively determine interlobar vein injury. 


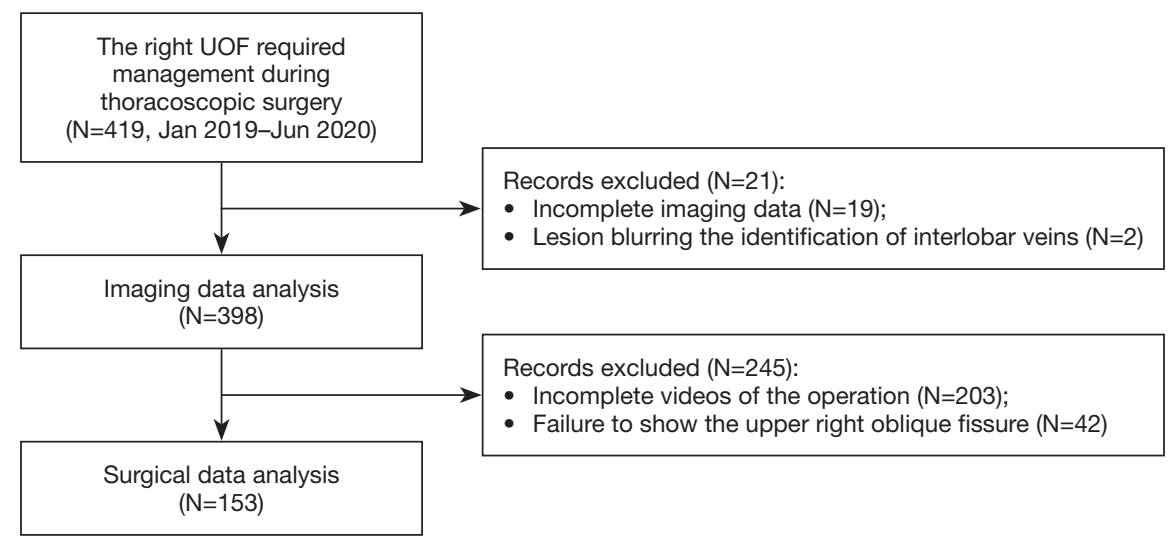

Figure 1 Flow diagram of participation. UOF, upper oblique fissure.
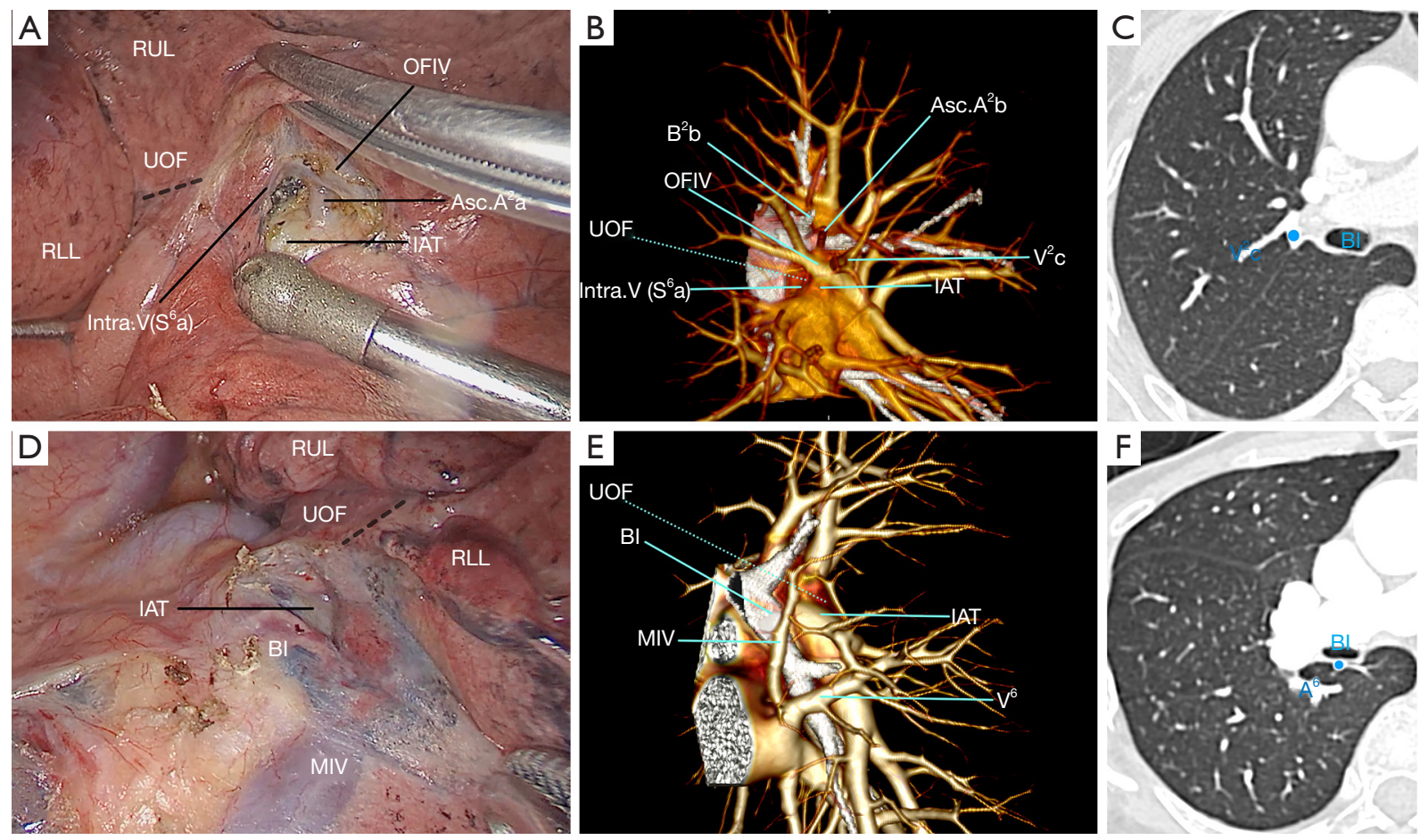

Figure 2 Trajectories of OFIV and MIV. (A) The OFIV trajectory is shown before the incision of the UOF. The OFIV originates from the $V^{2}$ c, travels between the right upper and lower lobes, and enters the UOF, producing the inferior lobe branch Intra.V $\left(S^{6} a\right)$ along its course. (B) Corresponding 3D-CTBA images of the surgical patient show the anatomical structure around the OFIV. The OFIV originates from the $\mathrm{V}^{2} \mathrm{c}$ segment and produces an Intra.V $\left(\mathrm{S}^{6} \mathrm{a}\right)$ branch on the surface of the IAT. (C) The blue dot indicates the measurement site of the OFIV in the CT lung window, which is where the OFIV originates from the $\mathrm{V}^{2} \mathrm{c}$. (D) The posterior mediastinal pleura was dissected during the operation to expose the MIV. The MIV originates from the inferior pulmonary vein and gradually enters the UOF posterior to the BI. (E) Corresponding 3D-CTBA images of the same patient show the anatomical structure around the MIV. (F) The blue dot indicates the measurement site of the MIV in the CT lung window, which is where the interlobar vein branches into $\mathrm{V}^{6}$. OFIV, oblique fissuretype interlobar vein; MIV, mediastinal-type interlobar vein; UOF, upper oblique fissure; Intra.V, intrasegmental vein; 3D-CTBA, threedimensional computed tomography bronchography and angiography; IAT, intermedial arterial trunk; CT, computed tomography; RUL, right upper lobe; RLL, right lower lobe; BI, bronchus intermedius; Asc. $\mathrm{A}^{2}$, ascending $\mathrm{A}^{2}$. 


\section{Statistical analysis}

Statistical analyses were performed using the SPSS (version 23.0; SPSS Inc., Chicago, IL, USA) and GraphPad Prism (version 6.0; GraphPad Software Inc., La Jolla, CA, USA). Quantitative data are expressed as the mean \pm standard deviation, and qualitative data are expressed as the number of cases (percentage). A receiver operating characteristic (ROC) curve was used to predict the possibility of single- or multibranched interlobar veins. A P value less than 0.05 was considered indicative of a significant difference.

\section{Results}

The clinical data of 419 consecutive patients who underwent thoracoscopic surgery from January $1^{\text {st }}, 2019$, to June $30^{\text {th }}$, 2020, were collected. Finally, 21 patients were excluded due to incomplete imaging data or lesions blurring the identification of interlobar veins, and 398 patients were enrolled. Among these patients, 237 received contrastenhanced CT scans, and 161 received plain CT scans. 3D-CTBA images were reconstructed with Deepinsight software (Key Laboratory of Intelligent Computing in Medical Image, Ministry of Education, Northeastern University, Shenyang, China). Then, the morphology and distribution of the interlobar vein in the UOF were independently analyzed by 2 thoracic surgeons. Two experienced radiologists measured the diameters of the interlobar veins in the lung windows of the contrast-enhanced CT images of 237 patients (window width $=1,400 \mathrm{HU}$, window position $=-500 \mathrm{HU}$ ). The images of 161 patients with noncontrast CT scans were analyzed only to determine interlobar vein subtypes. Furthermore, 153 patients with complete videos of the operation, including details of the UOF, were included for surgical data analysis. Participation at each stage is shown in the flow diagram (Figure 1).

\section{Interlobar vein subtypes}

The results of the 3D-CTBA image analysis of 398 patients showed diversity in the interlobar vein subtypes (Table 1). An OFIV was the most frequent type, accounting for $85.9 \%$ (342/398) of cases, and vastly outnumbered the MIV type $(13.8 \%, 55 / 398)$. Interlobar vein absence was observed in $0.3 \%$ of cases (1/398). Various main types could be further subdivided into 30 distribution manifestations. A total of $73.6 \%(293 / 398)$ of patients had branches distributed bilaterally into the upper and lower lobes, and $26.1 \%$
(104/398) had branches distributed only into the upper lobe. Additionally, 69.6\% (238/342) of OFIVs had Intra. $\mathrm{V}\left(\mathrm{S}^{6} \mathrm{a}\right)$ branches distributed into the lower lobe. All MIV types contained branches distributed into the RUL (55/55), originating from $\mathrm{S}^{2}$ or $\mathrm{S}^{1}$ veins.

The subtype analysis in Table 1 shows that $83.6 \%$ (286/342) of OFIVs had multiple branches. Single-branched OFIVs with only a $V^{2} t$ branch accounted for $16.4 \%$ (56/342) of all OFIV cases. Branches of the interlobar vein included $S^{2}$-related Intra.V ( $\left.S^{2} a\right), V^{2} a, V^{2} a 2, V^{2} b, V^{2} b 2$, and $V^{2} t, S^{1}$ related Intra.V $\left(\mathrm{S}^{1} \mathrm{a}\right), \mathrm{V}^{1} \mathrm{a}$, and $\mathrm{S}^{6}$ related Intra.V $\left(\mathrm{S}^{6} \mathrm{a}\right)$. A total of $56.4 \%$ (31/55) of MIV cases had multiple branches, $43.6 \%(24 / 55)$ of which were single-branched only with $\mathrm{V}^{2} \mathrm{t}$.

Figure 3 presents the common distribution of the interlobar veins. OFIVs ran in the UOF, branched into Intra. $\mathrm{V}\left(\mathrm{S}^{6} \mathrm{a}\right)$ and $\mathrm{V}^{2} \mathrm{t}$ branches, and then ran in the RUL and branched into $\mathrm{V}^{2} \mathrm{~b}, \mathrm{~V}^{2} \mathrm{~b} 2, \mathrm{~V}^{2} \mathrm{a}, \mathrm{V}^{2} \mathrm{a} 2$, ectopic $\mathrm{V} 1 \mathrm{a}$, or Intra.V ( $\mathrm{S}^{1}$ a) branches in some patients (Figure $3 A$ ). The MIV originated from $V^{6}$, coursed over the BI, extended upward along the posterior mediastinum, and branched into a $V^{2} t$ branch in the UOF. The distribution of other MIV branches in the RUL was similar to that of the OFIV except for an ectopic V1a (Figure 3B).

\section{Analysis of interlobar vein injuries}

As shown in Table 2, accidental injuries of the interlobar veins occurred in $19.1 \%(9 / 47)$ of patients with a complete UOF, $35.3 \%(6 / 17)$ of patients without a UOF, and 50.6\% (45/89) of patients with an incomplete UOF. The incidence of interlobar vein injury was significantly higher in patients with an incomplete UOF $\left(\chi^{2}=12.856, \mathrm{P}=0.02\right)$. In total, Intra.V $\left(\mathrm{S}^{6} \mathrm{a}\right)$ injury accounted for $91.7 \%$ (44/48) of OFIV injuries, and single-branched $\mathrm{V}^{2} \mathrm{t}$ injury accounted for $75 \%$ (9/12) of MIV injuries.

In the complete fissure group, of the 44 patients with OFIVs, 5 patients suffered from injury of Intra.V $\left(\mathrm{S}^{6} \mathrm{a}\right)$ during right upper lobectomy, including 1 with $\mathrm{V}^{2}$ a2 injury and 1 with Intra.V $\left(\mathrm{S}^{6} \mathrm{a}\right)$ injury during $\mathrm{S}^{2}$ resection, 1 with $\mathrm{V}^{2} \mathrm{a} 2$ injury during $\mathrm{S}^{2}+\mathrm{S}^{3}$ a resection, and 2 with Intra.V $\left(\mathrm{S}^{2} \mathrm{a}\right)$ injury during $\mathrm{S}^{2} \mathrm{~b}$ resection. No MIV branches were injured in patients with complete fissures.

In the fissure absence group, of the 14 patients with OFIVs, 4 patients suffered from injury of the Intra.V $\left(\mathrm{S}^{6} \mathrm{a}\right)$ branch of the OFIV during right upper lobectomy. Of the 3 patients with MIVs, 2 patients suffered from $V^{2} t$ and Intra. $\mathrm{V}\left(\mathrm{S}^{2} \mathrm{a}\right)$ injury during right lower lobectomy. 
Table 1 3D-CTBA analysis of subtypes of interlobar veins within the upper right oblique fissure in 398 preoperative patients

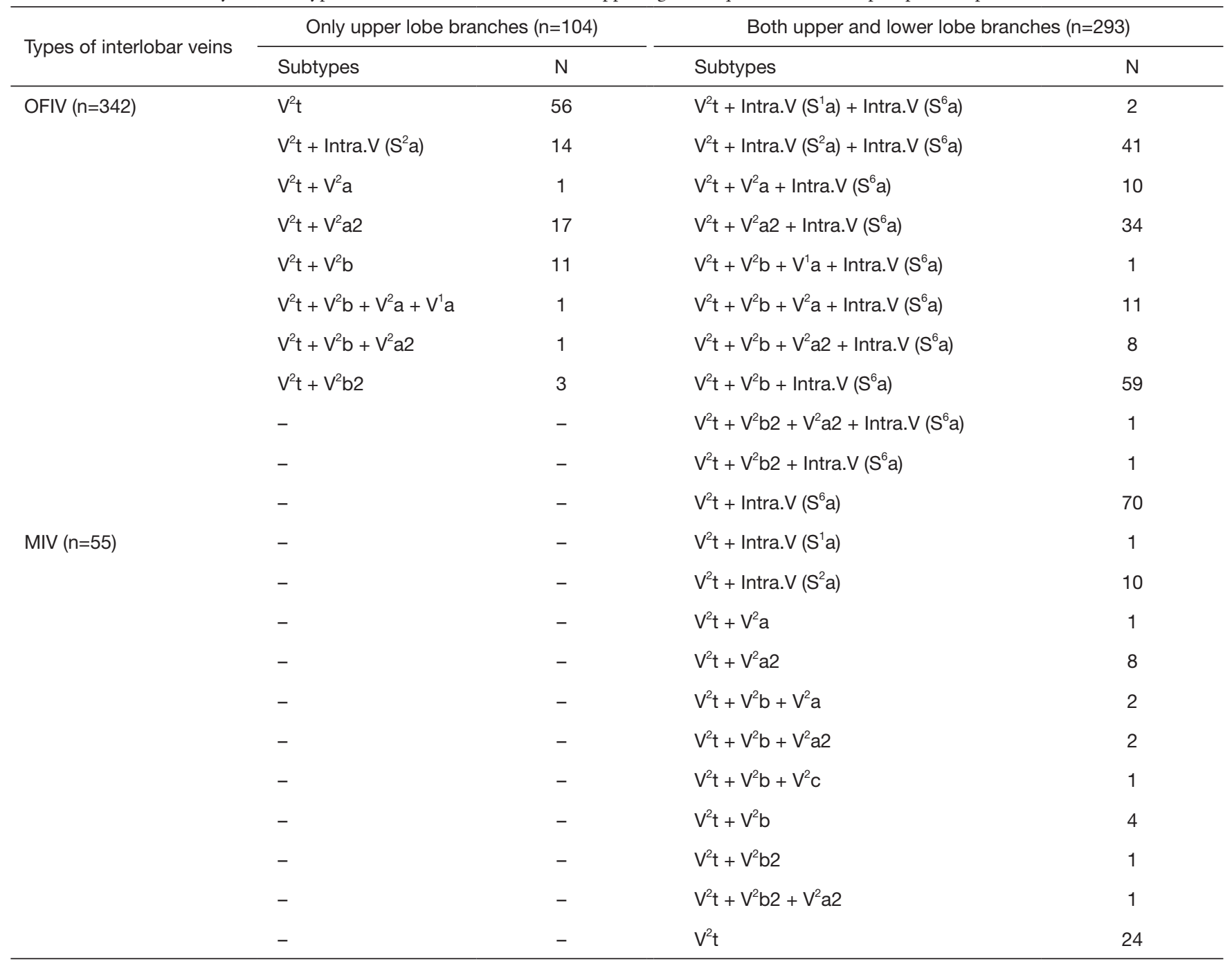

One patient had no interlobar veins. 3D-CTBA, three-dimensional computed tomography bronchography and angiography; OFIV, oblique fissure-type interlobar vein; MIV, mediastinal-type interlobar vein; Intra.V, intrasegmental vein.

In the incomplete fissure group, of the 70 patients with OFIVs, 28 patients suffered from Intra.V $\left(\mathrm{S}^{6}\right.$ a) injury during right upper lobectomy, and 6 suffered from Intra.V $\left(\mathrm{S}^{6} \mathrm{a}\right)$ injury during $\mathrm{S}^{2}$ resection. Of the 19 patients with MIVs, 10 patients suffered from injuries, including 4 with $V^{2}$ injury and 1 with $\mathrm{V}^{2} \mathrm{t}+\mathrm{V}^{2} \mathrm{a} 2$ injury during right lower lobectomy, 1 with $\mathrm{V}^{2} \mathrm{t}$ injury during right lower and middle lobectomy, and 3 with $V^{2}$ and 1 with $V^{2} t+\operatorname{Intra.} V\left(S^{2} a\right)$ injury during $\mathrm{S}^{6}$ resection.

\section{ROC curve of single- and multibranched interlobar veins}

Table 2 shows that Intra.V $\left(\mathrm{S}^{6}\right.$ a) injury accounted for $91.7 \%$ of OFIV injuries, and single-branched $V^{2}$ t injury accounted for $75 \%$ of $\mathrm{MIV}$ injuries. As evidenced from the interlobar vein subtypes (Table 1), the Intra.V $\left(\mathrm{S}^{6} \mathrm{a}\right)$ type was present in OFIVs with multiple branches. MIV injury mainly occurred in the single-branched $\mathrm{V}^{2} \mathrm{t}$ of the upper lobe. Therefore, we measured the diameters of single- and multibranched interlobar veins in the lung window on contrast-enhanced CT images in 237 of 398 patients (Table 3). In 206 patients with OFIVs, the diameter of the multibranched interlobar vein was $3.84 \pm 1.26 \mathrm{~mm}$. In 31 patients with MIVs, the diameter of the single-branched $\mathrm{V}^{2} \mathrm{t}$ was $1.81 \pm 0.42 \mathrm{~mm}$.

As shown in Figure 4, a ROC curve was applied to analyze the predictive value of interlobar vein diameter for 

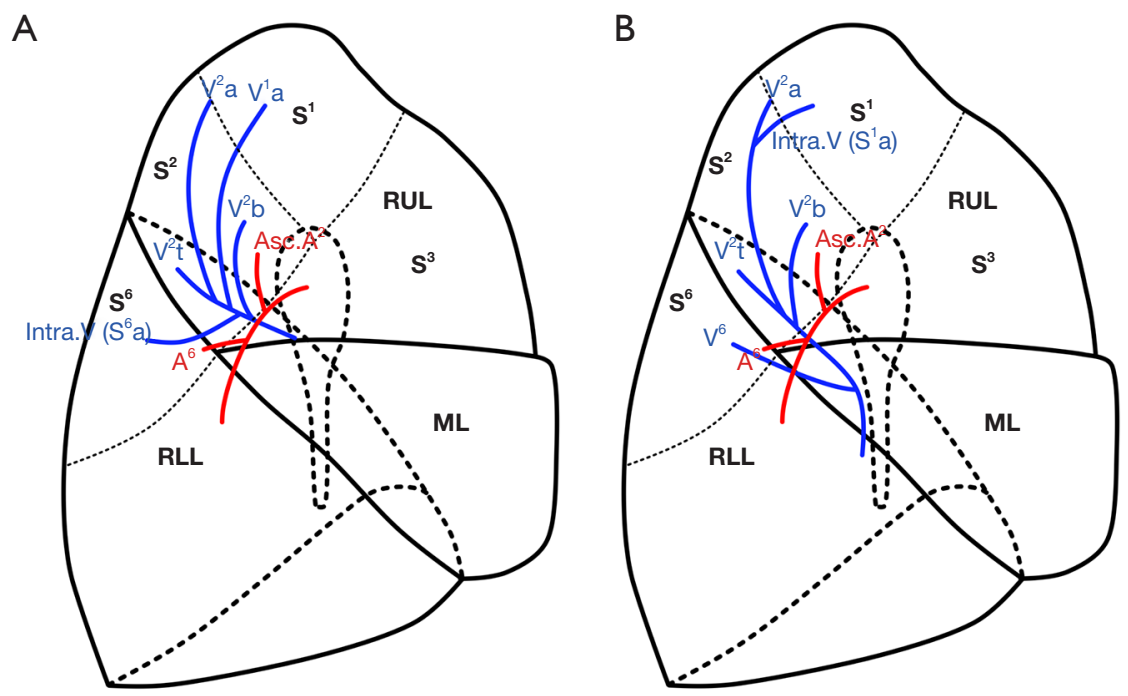

Figure 3 Schematic of the interlobar veins within the UOFs (lateral view of the right lung). The blue line represents the vein, and the red lines represent the IAT, $\mathrm{A}^{6}$, and Asc. $\mathrm{A}^{2}$. (A) The OFIV runs in the UOF, branches into the $\mathrm{V}^{2} \mathrm{t}$ and Intra.V ( $\mathrm{S}^{6}$ a), and then branches into the $\mathrm{V}^{2} \mathrm{~b}$ or $\mathrm{V}^{2} \mathrm{a}$ branches in the upper right lung or the $\mathrm{V}^{1}$ a branch in a few cases. (B) The MIV originates from the posterior mediastinum in the inferior pulmonary vein. After producing the $\mathrm{V}^{6}$ branch, the vessel continues ascending along the posterior BI and then enters the UOF and produces the $\mathrm{V}^{2} \mathrm{t}$ and Intra. $\mathrm{V}\left(\mathrm{S}^{1} \mathrm{a}\right)$ branches in a few cases. UOF, upper oblique fissure; IAT, intermedial arterial trunk; Asc. $\mathrm{A}^{2}$, ascending $\mathrm{A}^{2}$; OFIV, oblique fissure-type interlobar vein; Intra.V, intrasegmental vein; MIV, mediastinal-type interlobar vein; BI, bronchus intermedius; ML, middle lobe; RUL, right upper lobe; RLL, right lower lobe.

multibranched interlobar veins. The results showed that an OFIV diameter greater than $2.4 \mathrm{~mm}$ was a predictor of multibranched interlobar veins. The area under the ROC curve (AUC) was $94.3 \%$, with a sensitivity of $88.9 \%$ and a specificity of $92.3 \%(\mathrm{P}<0.001)$. A MIV diameter less than $2 \mathrm{~mm}$ indicated that the interlobar vein was a singlebranched $\mathrm{V}^{2}$ t. The AUC was $96.6 \%$, with a sensitivity of $100 \%$ and a specificity of $84.6 \%(\mathrm{P}<0.001)$.

\section{Discussion}

Intersegmental veins play a vital role in maintaining the ventilation/perfusion ratio of the pulmonary segment. The interlobar veins in the UOF involve multiple intersegmental veins. With the development of precise lung segment surgery, an increasing number of clinicians have paid attention to the diversity of interlobar veins. Our results also revealed 2 major types of interlobar veins, which contained up to 30 distribution patterns. The degree of completeness of the pulmonary fissure and the distribution of the interlobar vein were determinants correlated with the risk of intraoperative interlobar vein injury. The diameter of the interlobar veins on two-dimensional CT images can predict the branching mode of interlobar veins, which provides auxiliary support for the general classification in 3D-CTBA images.

Intersegmental veins were reported in a study by Yamashita (7), in which the emphasis was the central vein, and the branches of the interlobar veins were not analyzed separately. Although Yamashita defined the terminal branch of $\mathrm{V}^{2}$ as $\mathrm{V}^{2} \mathrm{t}(7)$, the study showed that $\mathrm{V}^{2} \mathrm{t}$ could accept drainage from other branches. We propose that $\mathrm{V}^{2} \mathrm{t}$ should be considered an independent branch that is only distributed in $\mathrm{S}^{2}$. Our results showed that only $16.4 \%$ of OFIVs were composed of the $\mathrm{V}^{2} \mathrm{t}$ branch alone, while $83.6 \%$ of interlobar veins had multiple branches, with Intra. $\mathrm{V}\left(\mathrm{S}^{6} \mathrm{a}\right)$ of the interlobar vein accounting for the highest proportion $(69.6 \%)$. In addition, the interlobar veins could also produce other branches, such as the rare ectopic $\mathrm{V}^{1} \mathrm{a}$ and Intra.V ( ${ }^{1}$ a) branches, accounting for $0.6 \%$ of all branches.

Some scholars consider a MIV as a RTPV that accepts drainage from $\mathrm{V}^{2}$ and $\mathrm{V} 3$, with an incidence of approximately $0.3-9.3 \%(8-10)$. In this study, the proportion of MIVs was $13.8 \%$, which was higher than that reported in previous studies. A possible reason is that the RTPV could 
Table 2 Analysis of interlobar vein injury in 153 patients underwent surgery related to the UOF

\begin{tabular}{|c|c|c|c|c|c|c|}
\hline \multirow{2}{*}{ Surgery type } & \multicolumn{2}{|c|}{$\begin{array}{l}\text { Injuries in the complete } \\
\text { fissure }(9 / 47)\end{array}$} & \multicolumn{2}{|c|}{ Injuries in the incomplete fissure $(45 / 89)$} & \multicolumn{2}{|c|}{ Injuries in the absent fissure $(6 / 17)$} \\
\hline & OFIV $(9 / 44)^{\dagger}$ & MIV (0/2) & OFIV (35/70) & MIV (10/19) & OFIV (4/14) & $\operatorname{MIV}(2 / 3)$ \\
\hline $\mathrm{RS}^{2}[15]$ & $V^{2} a 2(1 / 7)$ & - & Intra.V (S $\left.{ }^{6} \mathrm{a}\right)(4 / 7)$ & $0 / 1$ & - & - \\
\hline $\mathrm{RS}^{1} \mathrm{a}+\mathrm{S}^{2}[2]$ & - & - & $0 / 2$ & - & - & - \\
\hline $\mathrm{RS}^{2}+\mathrm{S}^{3} \mathrm{a}[1]$ & $\mathrm{V}^{2} \mathrm{a} 2(1 / 1)$ & - & - & - & - & - \\
\hline $\mathrm{RS}^{2} \mathrm{~b}[4]$ & Intra.V (S²a) (2/3) & - & - & $0 / 1$ & - & - \\
\hline $\mathrm{RLL}+\mathrm{ML}[3]$ & - & - & - & $V^{2} t(1 / 1)$ & $0 / 2$ & - \\
\hline \multirow[t]{2}{*}{$\mathrm{RS}^{6}[13]$} & $0 / 4$ & $0 / 1$ & $0 / 3$ & $V^{2} t(3 / 4)$ & $0 / 1$ & - \\
\hline & & & & + Intra.V $\left(S^{2} a\right)(1 /$ & & \\
\hline$R S^{6}+S^{9}+S^{10}[1]$ & - & - & $0 / 1$ & - & - & - \\
\hline $\mathrm{RS}^{6}+\mathrm{S}^{8} \mathrm{a}[1]$ & $0 / 1$ & - & - & - & - & - \\
\hline
\end{tabular}

Data are present as interlobar vein injured cases/total cases in each surgery subtype and interlobar vein type. ${ }^{\dagger}$, one patient had no interlobar veins. UOF, upper oblique fissure; OFIV, oblique fissure-type interlobar vein; MIV, mediastinal-type interlobar vein; RUL, right upper lobe; RS, right segment; RLL, right upper lobe; ML, middle lobe; Intra.V, intrasegmental vein.

Table 3 Contrast-enhanced CT showing types, diameters, and commonly injured branches of interlobar veins in 237 patients

\begin{tabular}{lcccc}
\hline Types of interlobar veins & Single-branched & Multi-branched & Lower lobe branches & Upper lobe branches \\
\hline OFIV $(n=206)$ & $1.83 \pm 0.57(n=26)$ & $3.84 \pm 1.26(n=180)$ & Intra.V $\left(S^{6} a\right)(n=152)$ & - \\
MIV $(n=31)$ & $1.81 \pm 0.42(n=13)$ & $3.69 \pm 1.21(n=18)$ & - & $V^{2} t(n=31)$
\end{tabular}

CT, computed tomography; OFIV, oblique fissure-type interlobar vein; MIV, mediastinal-type interlobar vein.

be more easily identified in 3D-CTBA images.

Interlobar vein injuries were most common in Intra. $\mathrm{V}\left(\mathrm{S}^{6} \mathrm{a}\right)$ branches of a multibranched OFIV and $\mathrm{V}^{2} \mathrm{t}$ of a single-branched MIV. The ROC curve revealed a close correlation between the diameter of the interlobar vein and the branching mode. An OFIV diameter larger than $2.4 \mathrm{~mm}$ often indicates multiple branches of the interlobar vein, and increased caution should be taken to prevent accidental injuries. A MIV diameter less than $2 \mathrm{~mm}$ often indicates a high risk of single-branched $\mathrm{V}^{2} \mathrm{t}$ injury.

In addition to the diameter and distribution pattern of the interlobar veins, the completeness of the UOF was also a risk factor for interlobar vein injury. Among 89 patients with an incomplete UOF, interlobar vein injury was common $(50.6 \%)$. For patients with incomplete or absent UOFs, the right superior pulmonary vein or inferior pulmonary vein was the primary anatomical structure to be divided when using the fissureless technique (11), which can easily cause interlobar vein injury (Figure 3). We suggest disassociating the anterior mediastinal vein branch $\left(\mathrm{V}^{1}\right)$ of the right superior pulmonary vein first when using the fissureless technique in an upper lobectomy, which helps preserve the interlobar veins. Other techniques include transecting the incomplete UOF above the OFIV in upper 

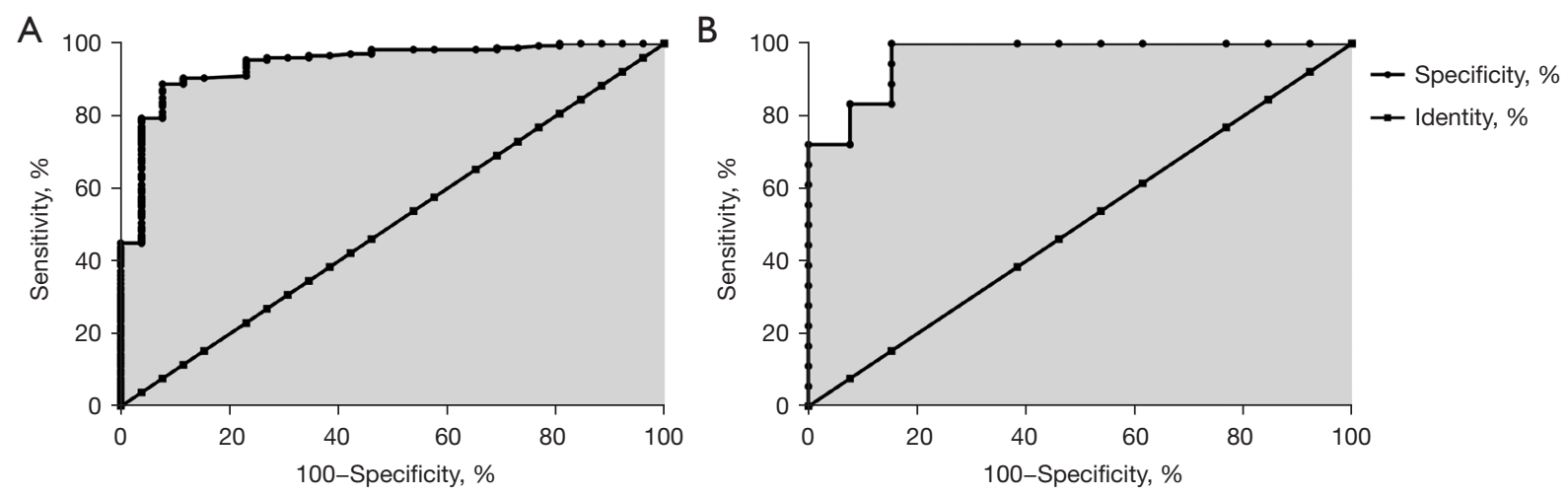

Figure 4 ROC curve of single- and multibranched interlobar veins based on diameter. (A) ROC curve of the oblique fissure-type interlobular vein. A diameter of the OFIV greater than $2.4 \mathrm{~mm}$ indicates a multibranched interlobar vein (AUC: 94.3\%). (B) ROC curve of the mediastinal-type interlobular vein. A MIV diameter less than $2 \mathrm{~mm}$ indicates a single-branched interlobar $\mathrm{V}^{2} \mathrm{t}$ vein (AUC: $96.6 \%$ ). ROC, receiver operating characteristic; OFIV, oblique fissure-type interlobar vein; AUC, area under the ROC curve; MIV, mediastinal-type interlobar vein.

lobe surgery and carefully identifying the MIV in the posterior mediastinum in lower lobe surgery.

There are some limitations to this study. First, this was a retrospective study performed at a single institution, and there was a possibility of inherent bias. However, to overcome this limitation, we aimed to include as many patients as possible using logical selection. Second, further analysis of the clinical complications caused by interlobular vein injury was not carried out. We are planning to implement this in the future by collecting more highquality data.

\section{Conclusions}

Diverse interlobar veins could be classified into the OFIV and MIV subtypes according to the distribution pattern. The diversity of the interlobar veins and the completeness of the UOF were noteworthy risk factors in surgery involving dissection of the UOF. The vein diameter on two-dimensional CT images and vein classification on 3D-CTBA images could provide supporting information to avoid accidental injury of interlobar veins.

\section{Acknowledgments}

We would like to thank American Journal Experts (https:// www.aje.com/) for English language editing.

Funding: This work was supported in part by the National Natural Science Foundation of China (81972175), Key Medical Research Project of Jiangsu Provincial Health
Commission (K2019002), Ethicon Excellence in Surgery Grant (HZB-20190528-13), and Jiangsu Province Natural Science Foundation (BK20201492).

\section{Footnote}

Reporting Checklist: The authors have completed the STROBE reporting checklist. Available at https://atm. amegroups.com/article/view/10.21037/atm-21-4913/rc

Data Sharing Statement: Available at https://atm.amegroups. com/article/view/10.21037/atm-21-4913/dss

Conflicts of Interest: All authors have completed the ICMJE uniform disclosure form (available at https://atm. amegroups.com/article/view/10.21037/atm-21-4913/coif). The authors have no conflicts of interest to declare.

Ethical Statement: The authors are accountable for all aspects of the work in ensuring that questions related to the accuracy or integrity of any part of the work are appropriately investigated and resolved. The study conforms to the provisions of the Declaration of Helsinki (as revised in 2013). The study was approved by the Ethics Committee of The First Affiliated Hospital of Nanjing Medical University (2021-SR-164). All patients signed an informed consent form before participating in the study.

Open Access Statement: This is an Open Access article distributed in accordance with the Creative Commons 
Attribution-NonCommercial-NoDerivs 4.0 International License (CC BY-NC-ND 4.0), which permits the noncommercial replication and distribution of the article with the strict proviso that no changes or edits are made and the original work is properly cited (including links to both the formal publication through the relevant DOI and the license). See: https://creativecommons.org/licenses/by-nc-nd/4.0/.

\section{References}

1. Hayashi K, Aziz A, Ashizawa K, et al. Radiographic and CT appearances of the major fissures. Radiographics 2001;21:861-74.

2. Raasch BN, Carsky EW, Lane EJ, et al. Radiographic anatomy of the interlobar fissures: a study of 100 specimens. AJR Am J Roentgenol 1982;138:1043-9.

3. Sedlackova Z, Ctvrtlik F, Miroslav H. Prevalence of incomplete interlobar fissures of the lung. Biomed Pap Med Fac Univ Palacky Olomouc Czech Repub 2016;160:491-4.

4. Yamada S, Suga A, Inoue Y, et al. Importance of preoperative assessment of pulmonary venous anomaly for safe video-assisted lobectomy. Interact Cardiovasc Thorac Surg 2010;10:851-4.

5. Hagiwara M, Shimada Y, Kato Y, et al. High-quality

Cite this article as: $\mathrm{Xu} \mathrm{X,} \mathrm{Wang} \mathrm{J,} \mathrm{Liu} \mathrm{Q,} \mathrm{Wen} \mathrm{W,} \mathrm{Xu} \mathrm{H,}$ Zhang W, Zhu Q, Chen Y, Chen L. Clinical significance of the diverse interlobar veins hidden in the upper oblique fissure. Ann Transl Med 2022;10(2):34. doi: 10.21037/atm-21-4913 3-dimensional image simulation for pulmonary lobectomy and segmentectomy: results of preoperative assessment of pulmonary vessels and short-term surgical outcomes in consecutive patients undergoing video-assisted thoracic surgery†. Eur J Cardiothorac Surg 2014;46:e120-6.

6. Kc S, Shrestha P, Shah AK, et al. Variations in human pulmonary fissures and lobes: a study conducted in nepalese cadavers. Anat Cell Biol 2018;51:85-92.

7. Yamashita H. Roentgenologic Anatomy of the Lung. Tokyo: Igaku-Shoin, 1978:53-6.

8. Lickfett L, Kato R, Tandri H, et al. Characterization of a new pulmonary vein variant using magnetic resonance angiography: incidence, imaging, and interventional implications of the "right top pulmonary vein". J Cardiovasc Electrophysiol 2004;15:538-43.

9. Arslan G, Dincer E, Kabaalioglu A, et al. Right top pulmonary vein: evaluation with 64 section multidetector computed tomography. Eur J Radiol 2008;67:300-3.

10. Akiba T, Morikawa T, Inagaki T, et al. A new classification for right top pulmonary vein. Ann Thorac Surg 2013;95:1227-30.

11. Nomori H, Ohtsuka T, Horio H, et al. Thoracoscopic lobectomy for lung cancer with a largely fused fissure. Chest 2003;123:619-22. 